\title{
Capsule Commentary on Agaronnik et al., Communicating with Patients with Disability: Perspectives of Practicing Physicians
}

\author{
Katarzyna Mastalerz, MD, FHM \\ VA Eastern Colorado Health Care System, Aurora, CO, USA.
}

$J$ Gen Intern Med 34(7):1291

DOI: $10.1007 / \mathrm{s} 11606-019-04987-8$

(c) Society of General Internal Medicine (This is a U.S. government work and not under copyright protection in the U.S.; foreign copyright protection may apply) 2019

$T$ he American Disabilities Act requires that clinicians ensure effective communication with patients with disabilities and mandates shared decision-making about preferred modes of communication. ${ }^{1}$ Agaronnik and colleagues tackled physician perspectives on this issue by interviewing 20 outpatient physicians about communicating with deaf, blind, and intellectually disabled patients. ${ }^{2}$

To describe their study and findings, the authors explicitly used the COnsolidated criteria for REporting Qualitative Research (COREQ) tool, a checklist for reporting important aspects of the research team, methods, context, analysis, and interpretations for interview-based qualitative research. ${ }^{3}$ Since qualitative research generally explores complex social phenomena and researchers often interact with study participants, an in-depth discussion of reflexivity is crucial. Here, four of the study participants were acquainted with the interviewer; it is important to understand that such acquaintances can create bias in responses. Using the COREQ tool and reporting these relationships is a strength of this publication; it lets readers make decisions about the trustworthiness of the data.

The study found that only a small minority of physicians had access to adaptive communication tools (American Sign Language interpreters, large font). Additionally, physicians rarely considered patient preferences for communication. Only four out of 18 physicians reported talking directly to intellectually disabled patients, preferring to talk to their caregivers. At least one physician assumed that intellectual disability meant lack of decision-making capacity about care.

These results should shake physicians to the very core. Communication is the soul of the patient experience. Moreover, communication failures are often at the root of medical errors that cause suffering, morbidity, and mortality. ${ }^{4}$ Patients

Published online April 22, 2019 with communication disabilities tend to be medically complex and have trouble accessing care. ${ }^{5}$ The idea that adaptive communication tools and shared patient-physician decision-making around communication are inconvenient or simply unnecessary is deeply troubling. Most physicians care for patients with overlapping communication disabilities; the quality of communication with these patients determines their outcomes. If our aim as physicians is to provide better quality care to our patients, it is imperative that we shed much more light on the supreme importance of communication in healthcare. We must do this soon and at all levels of physician education.

Corresponding Author: Katarzyna Mastalerz, MD, FHM; VA Eastern Colorado Health Care System, Aurora, CO, USA (e-mail: Katarzyna.Mastalerz@ucdenver.edu).

\section{Compliance with Ethical Standards:}

Conflict of Interest: The author has no conflicts of interest with this article.

\section{REFERENCES}

1. Civil Rights Division, Department of Justice. ADA requirements effective communication. https://www.ada.gov/effective-comm.htm. Published 2014. Accessed 6 March 2019.

2. Agaronnik N, Campbell EG, Ressalam J, Iezzoni, LI. Communicating with Patients with Disability: Perspectives of Practicing Physicians. J Gen Intern Med. 2019; (SPI 4911). https://doi.org/10.1007/s11606-01904911-0

3. Tong A, Sainsbury P, Craig J. Consolidated Criteria for Reporting Qualitative Research (COREQ): a 32-item checklist for interviews and focus groups. Int J Qual Health Care 2007;19(6):349-357.

4. Patient Safety. Joint Commission Online 2015; April 29, 2015:www. jointcommission.org. Accessed 6 March 2019.

5. Stransky ML, Jensen KM, Morris MA. Adults with Communication Disabilities Experience Poorer Health and Healthcare Outcomes Compared to Persons Without Communication Disabilities. J Gen Intern Med 2018;33(12):2147-2155.

Publisher's Note Springer Nature remains neutral with regard to jurisdictional claims in published maps and institutional affiliations. 